\title{
What are the probable predictors of urinary incontinence during pregnancy?
}

\author{
Nejat Demircan Corresp., ${ }^{1}$, Ülkü Özmen ${ }^{2}$, Fürüzan Köktürk ${ }^{3}$, Hamdi Küçük ${ }^{1}$, Şevket Ata ${ }^{4}$, Müge Harma ${ }^{2}$, \\ İnan İlker Arıkan ${ }^{2}$ \\ ${ }^{1}$ Faculty of Medicine Department of Family Medicine, Bülent Ecevit University, Zonguldak, Turkey \\ 2 Faculty of Medicine Department of Obstetrics and Gynecology, Bülent Ecevit University, Zonguldak, Turkey \\ 3 Faculty of Medicine Department of Biostatistics, Bülent Ecevit University, Zonguldak, Turkey \\ 4 Faculty of Science and Literature, Bülent Ecevit University, Zonguldak, Turkey \\ Corresponding Author: Nejat Demircan \\ Email address: nejatdemircan@gmail.com
}

Objectives: The frequency, predisposing factors and impact of urinary incontinence (UI) on quality of life (QoL) during pregnancy were investigated.

Materials and Method: A preliminary cross-sectional survey was studied among pregnant women between January and Jully of 2014. A total of 132 pregnant women were recruited using a questionnaire form for sociodemographic features, ICIQ-SF-Turkish version for the characteristics of UI and Wagner's Quality of Life scale to assess impact on QoL. $p<0.05$ was set significant.

Results: Urinary incontinence was present in 56 out of 132 pregnant women (42.4\%, UI-present group): mean age, $26.7 \pm 5.4$ y $(p=0.780)$; median height, $160 \mathrm{~cm}$ (min-max: 153-176, $p=0.037)$; median BMI, $28.7 \mathrm{~kg} / \mathrm{m}^{2}$ (min-max: 22.4-50.0, $\left.\mathrm{p}=0.881\right)$; urine leakage occurred per week once $(\mathrm{n}=18,32.1 \%)$, twice or thrice $(n=8,14.3 \%)$; per day few times $(n=14,25 \%)$, once $(n=5,8.9 \%)$ and always $(n=8,14.3 \%)$ with mainly a small amount of urine leakage $(n=33,58.9 \%)$ or a moderate $(n=4,7.1 \%)$. There were statistically significant relationships between QoL scores and frequency of UI $(p=0.002)$ or amount of leakage $(p=0.002)$. Impact on QoL scores ranged from mild $(n=33,58.9 \%)$, moderate $(n=4,7.1 \%)$ to severe $(n=4,7.1 \%)$ levels in daily life. UI impacted daily live activities in the sense that women were less likely to undertake activities outside their homes (23.2\%), it affected their working performance and friendships (8,9\%), their daily home activities (7.1\%), their general health status (12.5\%), their sexual relations (12.5\%), it made women more nervous or anxious (10.7\%), and $25 \%$ of women needed wearing pads or protectors. Anova, tukey, tamhane tests as the minimal important difference model yielded significant relevance between statistical analyses and clinical outcomes by using standard deviations $(p=0.001,0.001$ and 0.005 respectively). The following features were in favor of UI: Age (OR=0.845, $95 \% \mathrm{Cl} 0.268-2.669)$, being housewife $(\mathrm{OR}=1.800,95 \% \mathrm{Cl} 0.850-3.810)$, anemia $(\mathrm{OR}=0.939,95 \% \mathrm{Cl}$ $0.464-1.901)$, parity $(\mathrm{OR}=0.519,95 \% \mathrm{Cl} 0.325-0.829)$, miscarriage $(\mathrm{OR}=1.219,95 \% \mathrm{Cl} 0.588-2.825)$ and living in rural $(\mathrm{OR}=1.800,95 \% \mathrm{Cl} 0.887-3.653)$. Height $(p=0,037)$, educational status $(0.016)$, miscarriage $(0.002)$, parity $(0.006)$ and place of living $(0.020)$ were significant factors.

Conclusions: Many pregnant women are suffering from UI which warrant significant public health consideration in the region. Age, height, being housewife or graduated higher than primary, living in rural, parity, miscarriage, and anemia were the factors in favor of onset of UI. The authors plan a health promotion program in the region according to the results in order to give information to health care givers especially family physicians and educate women about the predictors of UI and pelvic floor 
excercises for primary prevention and secondary relief of UI during and after pregnancy and provide some hygienic supply to the poor in this aspect. 
WHAT ARE THE PROBABLE PREDICTORS

OF

URINARY INCONTINENCE DURING PREGNANCY?

6

Nejat Demircan $^{1 *}$, Ülkü Özmen², Fürüzan Köktürk ${ }^{3}$ Hamdi Küçük, Şevket Ata ${ }^{4}$, Müge Harma², İnan İlker Arıkan² Bülent Ecevit University ${ }^{1}$ Faculty of Medicine, Department of Family Medicine,

${ }^{2}$ Faculty of Medicine, Department of Gynecology-Obstetrics, ${ }^{3}$ Faculty of Medicine Department of Biostatistics, ${ }^{4}$ Faculty of Science and Literature

*Corresponding Author: Nejat Demircan, Bülent Ecevit University, Faculty of Medicine, 


\section{1-Introduction}

Urinary incontinence (UI) has been defined by the International Continence Society as 'the complaint of any involuntary leakage of urine'. Urinary incontinence occurs when intravesical pressure is lower than urethral closure pressure, and it may result from bladder or urethral impairment. When closure pressure is lower than bladder pressure, leakage occurs. It is not really known why, how and to what extent this disorder arises [1, 2]. Urinary incontinence is a common health problem worldwide. It could affect the life of patients and their families, with physical-hygiene, psychosocial and economic outcomes [3, 4]. By definition, any patient with even one episode of UI at any time is regarded as a case. Urinary incontinence is seen more frequently in females than males, and it can affect all ages [5]. It can also significantly impact quality of life (QoL) and be an economic burden (having to purchase sanitary pads, for example). Urinary incontinence can cause social withdrawal and impairment in QOL. It is accepted as a typical result of aging or being pregnant; thus, women often seek medical help when UI has reached its later stages [6-8].

There are some studies conducted on the prevalence of UI, and a large prevalence range has been reported. Rates of prevalence varied between $12 \%$ and $53 \%$ in a review of 48 epidemiological studies. The median prevalence of female UI was determined to be $27.6 \%$ (range: $4.8 \%-58.4 \%$ ) in different non-institutional populations. Its prevalence during pregnancy ranged from 32\%-64\% $[5,7,9,11]$. The prevalence of UI increases as term approaches during pregnancy (12\% at the end of pregnancy) and decreases after childbirth [1].

The studies on UI among women in Turkey revealed a prevalence rate of $16.4 \%-49.7 \%$. Also, the overall prevalence of UI in a study of pregnant women by Kocaoz et al. was $27 \%$. This variation is most likely due to alterations in study design, questionnaire type, selection criteria and definitions [12-16].

Several risk factors for UI have been defined, such as age, childbirth, menopause and smoking. Urinary incontinence is less frequently found in nullipara women. Individual variation in the predisposition for UI has also been noted [15]. The prevalence reaches a 
maximum during pregnancy and diminishes postpartum. Caesarean sections seem to be associated with lower rates of stress incontinence than vaginal deliveries. The suspected probable risk factors are likely to have an effect at different times and on different portions of the urethral sphincter complex [16-22]. Studies have shown that experiencing UI during pregnancy is a major risk factor for persistence of the problem later in life [1, 23, 24].

Some pregnant patients have been admitted to emergency room at the centre with complaints of UI mixed with early membrane rupture. It is necessary to strictly follow up pregnant women as well as other patients during periodical examinations in all aspects of health, including UI. In general, UI is unfortunately considered to be a typical occurrence during pregnancy, and it might persist long after delivery.

\section{2-Aim}

The authors aimed to investigate the frequency of UI among pregnant women as well as the possible etiologic or predisposing factors and its impact on QoL, including social and health effects in the region. Then, on the basis of results obtained an education program would be promoted for the women and health care givers to improve health attitude towards the issue.

\section{3-Patients and Methods}

The present study was a preliminary investigation constructed as a cross-sectional survey. It was carried out at the obstetrics outpatient unit of the Gynecology and Obstetrics Department at Bülent Ecevit University Ibni Sina Health and Research Center. This is a referral centre for the city of Zonguldak and its towns and villages. The annual count of births carried out at the centre ranged between 534 and 880 from 2009-2014. From January to December of 2013, the total number of births at the centre was 534. The study was carried out from January to July of 2014 to obtain a general overview of UI in the region. As a simple randomization technique, a table of random numbers was used to select patients. A total of 132 pregnant women were eligible according to the inclusion and exclusion criteria. In order to collect the data, three surveys were used: (1) A questionnaire form that defined the demographic and personal features of the participants according to the relevant literature, (2) The Turkish version of the International Consultation on Incontinence Questionnaire Short Form (ICIQ-SF) [Supplement 1, $\$$ ] and (3) Wagner's Quality of Life (QoL) scale [Supplement 2, $\mu][16]$. 
The questionnaire was composed of information about socio-demographic features (age, height, weight, BMI, educational status and occupational information). It also included questions pertaining to obstetric and urogynecologic history (gravidity; parity; type of birth; instrumented delivery; birth weight of the heaviest infant; symptoms related to menopause; hormone replacement therapy; prior gynecologic operation; any infection during the present or previous pregnancies; episiotomy; intrauterine growth retardation; history of urinary system disease, including urinary infections; urinary system surgeries undergone; history of UI in previous pregnancies and the frequency of voiding per day). The questionnaire also included information regarding personal habits (smoking and usage of alcoholic beverages or caffeinated drinks, such as cola, coffee or tea).

The authors also used the ICIQ-SF, a concise and disease specific questionnaire that has been widely used [16]. The Turkish version of the ICIQ-SF was validated by Cetinel et al. (2004). We used the parts related to the frequency and severity of urine leakage [15, 16].

The researchers also carried out Wagner's QoL scale, introduced by Wagner et al. (1996). The Turkish version of the scale was developed by Karan et al. (2000). This scale constitutes 28 questions related to the presence of UI in pregnant women and impact of UI on their daily lives and in psychosocial situations. Participants were asked to answer each question by selecting one of the following options: 'no', 'mild', 'moderate' and 'severe'. The answers were scored as $0,1,2$ and 3, respectively. Consequently, a total score of 0 signified that there was not any incontinence or any psychosocial problem, 1-28 denoted the presence of a mild disorder, 29-56 denoted a moderate disorder and 57-84 indicated a severe disorder [16, 25].

The study protocol was approved by the Ethical Committee at the BEU Faculty of Medicine according to the Declaration of Helsinki, with approval number 2011-99-19/07 [Supplement 3, $\Psi$ ]. A written informed consent form [Supplement 4, $ซ]$ was signed by each participant. The questionnaires were carried out at the obstetrics-gynecology outpatient clinic via face-toface interviews with participants. Two resident physicians were trained in the administration of questionnaires. It took about 40-50 minutes to interview each participant. Ethnicity was not indicated because all patients shared a similar ethnic background.

\section{Inclusion and Exclusion Criteria}


Pregnant women above 18 years of age without any acute or chronic disease were included in the study. Pregnant women in the high-risk category were excluded. Individuals were also excluded based on the following: the presence of any systemic or chronic diseases, such as diabetes mellitus or any condition of increased blood glucose levels or disturbed glucose states; hypertension (blood pressure over 125/85 $\mathrm{mmHg}$ ); hepatitis or any state with elevated liver enzymes; any neurological disease; Cushing's disease; asthma; cardiac failure; central nervous system disorders or urinary tract infection or stones, etc. Women with previous urogynecologic diseases and obvious neuropathies leading to UI were also excluded from the study. Other risk factors for UI were also asked, including smoker status and use of medications (such as alpha-blockers and cholinergic or anticholinergic drugs), sedatives, myorelaxants, diuretics and angiotensin-converting enzyme inhibitors. Patients who smoked and used such substances were also excluded from participation.

All data were analyzed using SPSS Version 19.0 for Windows (SPSS Inc., Chicago, Illinois, USA). Categorical variables were presented as frequencies and percentages, and continuous variables were expressed as mean $\pm \mathrm{SD}$. The normality of the distribution of continuous variables was tested using the Shapiro-Wilk test. Differences in continuous variables between groups were examined using the independent sample t-test or nonparametric MannWhitney $U$ test. The comparison of results between three or more groups was made using the Kruskal-Wallis test. The Dunn's test was used as a post hoc test if the Kruskal-Wallis test was statistically significant. Categorical values were compared using a chi-square test. Multivariate logistic regression analysis was performed to assess independent risk factors. A p-value of $<0.05$ was considered statistically significant.

\section{4-Results}

Fifty-six women (42.4\%) declared the presence of UI, so they were categorized as the UIpresent group. Seventy-six women (57.6\%) did not experience UI, so they were classified as the UI-absent group.

\section{Socio-demographic Features:}

Age: The majority of participants were young pregnant women in the age group of 21-29 years. The mean age of all participants was $27.5 \pm 5.1$ years. Two age groups were formed: 18-35 and $\geq 35$ years. There was no significant difference in terms of existence of UI with 
respect to age groups ( $\mathrm{p}=0.146$, table 1$)$. Age was a possible predictor in developing UI, but there was no statistically significant relationship between the existence of UI and age $(\mathrm{OR}=0.845,95 \%$ CI 0.268-2.669, $\mathrm{p}=0.782$, table 6).

Height: There was a significant difference between UI-present and UI-absent groups according to body height ( $\mathrm{p}=0.037$, table 1$)$.

BMI: There was no significant difference between UI-present and UI-absent groups according to BMI values $(\mathrm{p}=0.881$, table 1$)$. BMI was in favor of onset of UI, but not significant statistically in logistic regression analyses $(p=0.998, O R=1.000,95 \%$ CI 1.000 1.000, table 6).

Occupational status: Over two-thirds of the participants were housewives (that is, they had no occupation other than carrying out housework) in the UI-present group $(n=39,69.6 \%)$ and UI-absent group $(n=53,69.7 \%)$. There was no significant difference in terms of the occurrence of UI between those working and those not working $(\mathrm{p}=0.122$, table 1$)$. Logistic regression analyses revealed that occupational status might be a predictor of the occurrence of UI $(\mathrm{OR}=0.897,95 \%$ CI $0.392-2.055)$, but it was not statistically significant $(\mathrm{p}=0.798$, table 6).

Educational level: Being graduated higher than primary school was a significant feature between UI-present and absent groups ( $\mathrm{p}=0.016$, table 1). The number of primary school graduates in UI absent group $(n=32)$ was significantly more than UI-present $(n=11, p=0.01)$. The educational levels in 2013 census of Zonguldak have been revealed as 6\% illiterate, 16 $\%$ literate but not graduated at any school, $26 \%$ primary school, 23\% intermediary, 18\% high school and $11 \%$ any university degree graduates, whereas in the current study, similar results were found but not any illiterate (table 1). In the present study the number of primary school graduates in UI-present (19.6\%) and intermediate school graduates in UI absent $(6.6 \%)$ were lower compared to general distribution in the area. Also university degree graduates had different distribution. All participants in the study had some degree of graduation. The number of primary school graduates in UI absent group was significantly more than UI-present.

Place of living: The location (rural vs urban) of one's residence was significant in logistic regression analyses $(\mathrm{p}=0.020,95 \%$ CI 0.887 and 3.653, table 6). Hence, living in a rural area was in favor of occurrence of UI. Zonguldak is a city with population size of 326374 (58.4 

$\%$ ) in rural and 232,200 (41.6\%) in urban. Our study population had rural predominance (76/56). Ratio of rural vs urban was 36/20 in UI-present group, and 36/36 in UI absent. Table of random numbers was used to overcome selection bias. Pregnant women who came from rural might have chosen the hospital because of some economic, social or social security preferences instead of special hospitals, or other health care providers.

Gestational Features:

182

With respect to parity, gestational weeks, multiple pregnancies, interval between pregnancies and the occurrence of miscarriage or anemia, the results of statistical analyses are presented in Table 2. There was no significant difference according to gestational weeks or trimesters because all participants were in their third trimester $(p=0.908)$. We did not encounter any significant difference between UI-present and UI absent groups in the occurrence of UI according to parity values $(\mathrm{p}=0.358)$, history of multiple pregnancies $(p=0.747)$ or interval between previous pregnancies $(p=0.283$, Table 2$)$ either. There were statistically significant relationships according to history of miscarriage $(\mathrm{p}=0.002, \mathrm{OR}=$ $1.219,95 \%$ CI $0.588-2.825)$, and also parity values $(\mathrm{p}=0.006, \mathrm{OR}=0.519,95 \%$ CI 0.325 0.829 , table 6) in logistic regression analyses.

Previous observations have suggested that parity, or pregnancy itself, might contribute to the onset of UI independent of the mode of delivery. Consistent with the literature, the present study denoted that parity was statistically a predictor of the onset of UI (table 6$)[1,15]$.

Trimesters: All participants in the present study were in the same (third) trimester. Most of the patients had been referred to the health center, a tertiary level of care, by their primary or secondary healthcare providers in the region. This referral is often carried out at a time near suspected birth. As stated above, no statistical difference was found with respect to trimesters because all of the participants were in their third trimester $(p=0.09$, table 2$)$. Patients may have preferred to visit the health center shortly before delivery.

Miscarriage: The relationship between history of miscarriage and presence of UI was statistically significant $(\mathrm{p}=0.041$ in chi-square test, table 2 and $\mathrm{p}=0.002$ in logistic regression analysis, table5).

When the history of previous pregnancies was further analyzed, no statistically significant relationship was found with respect to history of preterm labor $(\mathrm{p}=0.474)$, anomalous babies $(p=0.827)$, chronic disease - if present — during previous pregnancies $(p=0.828)$, or anemia 
207

208

209

210

211

212

213

214

215

216

217

218

219

220

221

222

223

224

225

226

227

228

229

230

231

232

233

234

235

236

237

$(\mathrm{p}=0.862$, Table 2). Regarding the present pregnancy, there was no significant difference in the occurrence of UI according to vitamin usage $(\mathrm{p}=0.166)$, weight gain $(\mathrm{p}=0.995)$, exercise $(\mathrm{p}=0.099)$, sexual intercourse $(\mathrm{p}=0.366)$.

Anemia: Participants who had mean blood hemoglobin values below $11.5 \mathrm{mg} / \mathrm{dl}$ were accepted as anemic during the study. There was no significant difference in the presence of anemia between UI-present and absent groups ( $\mathrm{p}=0.862$, table 2 ). Prior to the onset of the study, any chronic disease patients were excluded from participation. Anemia presented in the current study most likely developed during pregnancy due to insufficient iron intake, though women deficient in iron, folate and vitamin B12 were prescribed supplements beforehand in order to participate in the study. Logistic regression analysis revealed that anemia was indicated in favor of the onset of UI; as the anemia worsened, the possibility of developing UI increased (table 6). However, it was not significant in logistic analyses (table $6)$.

Impact of UI on QoL: With respect to frequency of UI reported in the UI-present group, there were occasions of urinary leakage once a week or less in 18 participants $(32.1 \%)$, twice or thrice a week in 8 participants (14.3\%), once a day in 5 participants $(8.9 \%)$, a few times a day in 14 participants $(25.0 \%)$ and constantly throughout the day in 8 participants $(14.3 \%$, table 3$)$.

Among those in the UI-present group, mainly a small amount of urine leaked in 33 participants (58.9\%), a moderate amount leaked in 4 participants (7.1\%) and large amount in 4 also $(7.1 \%$, table 3$)$. The amount of urine leakage was assigned by the number of hygienic pads used.

With respect to Wagner's QoL scores, the majority of UI-present women $(\mathrm{n}=33,58.9 \%)$ experienced mild urinary incontinence symptoms, some of them experienced moderate $(n=4,7.1 \%)$ and $7.1 \%$ of women $(n=4)$ experienced severe, whereas urinary incontinence did not affected their QoL in $26.8 \%$ of women with UI ( $n=15$, Table 4). There were statistically significant relationships between QoL scores and frequency of UI as well as the amount of leakage ( $\mathrm{p}=0.002$ and $\mathrm{p}=0.002$, respectively, Kruskal-Wallis test). Thus, in general, the majority reported having mild UI.

UI impacted daily live activities in the sense that women were less likely to undertake activities outside their homes (23.2\%), it affected their working performance and friendships 
238

239

240

241

242

243

244

245

246

247

248

249

250

251

252

253

254

255

256

257

258

259

260

261

262

263

264

265

266

267

268

$(8,9 \%)$, their daily home activities $(7.1 \%)$, their general health status $(12.5 \%)$, their sexual relations (12.5\%), it made women more nervous or anxious (10.7\%), and $25 \%$ of women needed wearing pads or protectors (Table 5).

Whether the outcomes were clinically relevant in the sense that the statistically relevant differences that we found were also of meaning in the clinic, we tested we tested with the minimal important difference method. So, we used the standard deviations given in table 4 to calculate whether the found relationships were clinically relevant as well. We transformed standard deviations given in table 4 to standard errors, and performed Anova test for the statistics, then we found that there were significance between them $(\mathrm{p}=0.001$, table 7$)$. Then, we accomplished Tukey and Tamhane tests: The statistically significant results gained from kruskall wallis analyses (table 4) for impact of urinary incontinence on QoL of pregnant women were relevant with clinical outcomes; they were all significant (table8). Thus, we could state that there was a statistical relevance between results of QoL tests and clinical outcomes.

Statistical importance tests were also performed for history of preterm labor $(\mathrm{p}=0.341)$, babies small for gestational age ( $\mathrm{p}=1.000)$, anomalous babies $(\mathrm{p}=1.000)$, alcohol intake (no participant had alcohol intake), vitamin intake $(\mathrm{p}=0.166)$, exercise $(\mathrm{p}=0.099)$, age of first birth $(p=0.390)$ and sexual intercourse $(p=0.366)$. None of these variables were significantly related to the occurrence of UI.

According to logistic regression analyses, the following factors were designated to favor the existence of UI: age ( $\mathrm{OR}=0.845,95 \%$ CI $0.268-2.669)$, occupational status $(\mathrm{OR}=1.800,95 \%$ CI $0.850-3.810)$, anemia ( $\mathrm{OR}=0.939,95 \%$ CI $0.464-1.901)$, parity $(\mathrm{OR}=0.519,95 \%$ CI $0.325-0.829)$, miscarriage in previous pregnancies $(\mathrm{OR}=1.219,95 \% \mathrm{CI} 0.588-2.825)$ and place of living (rural vs urban, $\mathrm{OR}=1.8,95 \%$ CI 0.887-3.653).

Miscarriage, parity and place of living (living in a rural settlement) were statistically significant predictors of the occurrence of UI ( $p=0.002, p=0.006$ and $p=0.020$ respectively, table 6).

\section{5-Discussion}

The rate of UI in the current study (42.4\% among 132 pregnant women) is consistent with UI studies among women in Turkey that have revealed a prevalence rate of $16.4 \%-49.7 \%$ [12-16]; this study is also consistent with data in the literature that show a prevalence rate of 

32-64\% [26-28]. However, in a study by Sharma et al. (2009), UI prevalence was cited at a rate of $25.8 \%$ in 240 pregnant women [29]. The most thoroughly studied risk factors have been age, parity and obesity. The occurrence of UI increases with age [1, 30-35]. How these factors (and others) performed in the current study is discussed below:

In the present study, mean age was younger and a possible predictor, but not a significant factor for the onset of UI contrary to other studies. (Table 1 and 6) $[1,35]$.

There was a significant difference between UI-present and absent pregnant women with respect to height, consistent with the literature ( $\mathrm{p}=0.037$, table 1$)$. Vahdatpour et al. found a direct and significant relationship between height and rate of urine leakage. Taller women were more prone to develop prolapse and weakening of pelvic floor muscles; consequently, they were more likely to develop UI and experience increased severity of complications [36]. Obesity or increased BMI is a predisposing factor in the onset of UI [1, 32-33, 37]. However, the current study revealed that BMI was in favor of presence of UI but not a significant factor (table 1 and 6) consistent with studies by Seshan-Muliira (2013) and Vahdatpour et al. (2013) [34, 36]. They found that age and BMI similarly were not significant predictors of UI. This was contrary to several investigations in which BMI was reported to be one of the major factors in determining UI, because increased abdominal weight led to continuous strain over pelvic tissues, causing pelvic muscles to be persistently stretched and muscles and nerves to weaken over time [38, 39].

In the current study, the majority of the women with UI $(69.6 \%)$ dealt with household chores. Similar to the present, in the UI investigation by Seshan and Muliira, the majority of women who experienced an onset of UI worked within the home as either housewives or housemaids/helpers (57\% and 16\%, respectively, $\mathrm{p}<0.01$ ) [34].

All participants in the study had some degree of graduation. The number of primary school graduates in UI absent group was significantly more than UI-present though we tried to avoid selection bias. Similar to the current study, Seshan and Muliira found that majority of their study group were mostly at the age group of 50 to 60 years (43\%), with low levels of education (primary school or lower (53\%), working as housewives $(57 \%)$ or housemaids/helpers (16\%) and with BMI above the normal limit (52\%) [34]. Being a primary school or intermediate school graduate or living in a rural area could be regarded as some features of low socio economic level that might effect on living conditions including 
300

301

302

303

304

305

306

307

308

309

310

311

312

313

314

315

316

317

318

319

320

321

322

323

324

325

326

327

328

329

health states. This was similar to the study by Seshan and Muliira with respect to living in low socio-economic conditions [34].

\section{Obstetrical Features:}

In the current study, parity and miscarriage were significant predictors of onset of UI, but trimester was not. Hansen et al. demonstrated that, with adjustment for potential risk factors, UI in pregnant women was 3.3 times more prevalent than UI occurring in a control group of nulliparous women [40]. In a study by Abdullah B et al., frequency of UI was $34.3 \%$ and trimester was not a significant factor for occurrence of UI [41]. In the study by Seshan and Muliira, the participants with UI had one or more miscarriages in the past (79\% of the total participants, $\mathrm{p}<0.01$ ), supporting the current findings. Thus, miscarriage was a predictor of the occurrence of UI [34]. Findik et al. stated in their study that among women who had experienced miscarriage, the rate of stress incontinence was significantly high. In addition, as the number of miscarriages increased, the rate of stress incontinence also increased, but the rate of urgent UI was not influenced by miscarriage [38]. However, in the current study, distinctions between types of UI were not made.

In the present study, anemia was a predictor for the presence of UI but not significant. Actually we do not know if anemia have led to or why and how anemia might lead to UI. Most probably it was not a primary cause but could be regarded as a secondary in development: In the study by Pahor M, Manini T and Cesari M (2009), they stated that anemia was associated with reduced physical performance and muscle strength. They showed the decreases in skeletal muscular strength measures occurred in the presence of anemia [42]. Sangsawang and Sangsawang (2016) stated that any derangement of pelvic floor muscles were important in development of UI [43]. Walker GJA and Gunasekara P (2011) said that the overall prevalence of UI was $28.7 \%$ (ranging from 5-70\%) and together with Scherf C et al (2002) and Bodner-Adler B et al (2007) they stated that the common factors that have been reported to be associated with UI in women included standards of living, poor nutrition (causing poor tissue tensile strength), anemia and regular physical heavy work. Moderate and severe anemia also appears to be a risk factor associated with pelvic organ prolapse leading to UI. The other factors included age, obesity, and menopause. We could say anemia in addition to other poor socioeconomic features might lead to a 
330

331

332

333

334

335

336

337

338

339

340

341

342

343

344

345

346

347

348

349

350

351

352

353

354

355

356

357

358

359

decrease in pelvic floor muscle performance or pelvic organ prolapse at some level and then onset of UI [44-46].

Contrary to Zhu L et al, the authors could not state any decision about significance with respect to alcohol intake because no participant had used alcohol [35].

QoL scores: Among social complaints impacted by UI, those related to wearing pads or protectors were the most encountered requirements leading to increase in economic cost consistent with the study by Kocak et al [6]. There were significant relationships between QoL scores and both the frequency and the amount of UI $(\mathrm{p}=0.002$ and $\mathrm{p}=0.002$, respectively), whereas in the study by Kocaoz et al., there was no significant relationship between the amount of UI and mean QoL score; however, there was a statistically considerable relationship between frequency of UI and mean QoL score, signifying that increased frequency of UI significantly impacted women's QOL [16]. Minassian et al stated that UI had moderate to severe impact on QoL in $10 \%$ to $22 \%$ of the individuals [5]. Abdullah B et al stated that more than $50 \%$ of women at their third trimester felt that UI did not impact on their daily activities at all; however $10 \%$ of women felt greatly affected [41]. Seshan and Muliira found that the majority of women with UI experienced symptoms at a moderate level (78\%) and others rated the symptoms as mild (22\%) [34]. Adamczuk et al. studied stress UI and its impact on QoL. They found that UI turned out to be a depressing factor, and it was associated with lower QoL [47].

Restrictions of the study: All of the participants were in their third trimester. This is probably because they came to the hospital at a time shortly before giving birth due to social, cultural or most probably economic reasons. Some women were also unwilling to talk about their symptoms because of being ashamed and thus chose not to participate. Therefore, the rate of UI cases might have been underestimated.

Treatment options: Treatment options, such as pelvic floor muscle exercises, have been available for UI and discussed in the relevant literature, though they were not investigated in the current study. Pelvic floor muscle exercise is a safe and effective treatment for UI during pregnancy, without significant adverse effects [27]. Hence, dealing with UI in pregnancy is important with respect to daily healthcare services from a therapeutic point of view [43].

\section{6-Conclusions}


There have been many UI studies performed in women; however the present study was performed among pregnant women. Many pregnant women are suffering from UI designated as different daily life impactions which warrant significant public health consideration in the region of Zonguldak, Turkey. The majority of participants reported having mild UI that caused life style changes in which requirement of wearing pads or protectors was mostly encountered increasing economic cost. Frequency and amount of UI were the significant factors in experiencing UI symptoms. Age, height, parity, miscarriage, occupational status and anemia were the factors in favor of onset of UI. Among them, height, miscarriage and parity were the significant predictors of onset of UI in pregnancy. Though it was not significant in logistic analyses, anemia - as a sign of poor socio economic level and poor health- was noted to be a predictor of UI. Place of settlement (rural), educational statuses (being graduated higher than primary school) were significant factors in favor of UI presence. It is necessary to pay more attention to diagnose UI during pregnancy and to understand its impact on women's health. Health care givers especially family physicians need to educate pregnant women about the risk factors of UI to use proper treatment options such as pelvic floor exercises. The predictors reported in this study could be useful to enhance primary prevention and secondary relief in the pregnant women prone to develop UI. The authors planned to implement education programs for women that UI is not a disgraceful and desperate situation and for care givers or physicians that UI is not an unpredictable and unavoidable or remediless health trouble. Hygienic pads or related health materials could be supplied by offices of ministries of health or family and social development to women of low socio economic level. For these social programs, we will introduce a health promotion plan to initiate a project at local health administer office together with family and social development administer according to results of this pilot study so that we will design another study to see the outcomes after the project.

Acknowledgements: The researchers hereby would like to thank Assist Prof Dr Alaaddin Çakır, Mr Abdullatif Kaya, Mr Tahir Güven, Mr Yunis Yıldırım, Dr Belis Bengü Yıldırım and Dr Suat Biçak and the other the staff of the hospital for convenience of the study at Bulent Ecevit University Faculty of Medicine and Ibni Sina Health Center of the University, Zonguldak, Turkey and -first of all-members of their families.

\section{References:}


391

392

393

394

395

396

397

398

399

400

401

402

403

404

405

406

407

408

409

410

411

412

413

414

415

416

417

418

419

1-Fritel X, Ringa V, Qubioeuf E, Fauconnier A. 2012. Female urinary incontinence, from pregnancy to menopause: a review of epidemiological and pathophysiological findings. Acta Obstetricia et Gynecologica Scandinavica 91:901-910

2- DeLancey JOL. 2010. Why do women have stress urinary incontinence? Neurourology and Urodynamics 29:13-7

3- Hunskaar S, Lose G, Sykes D, Voss S. 2004. The prevalence of urinary incontinence in women in four european countries. BJU International 93:324-30

4- Abrams P, Cardozo L, Fall M, Griffiths D, Rosier P, Ulmsten U, van Kerrebroeck P, Victor A, Wein A. 2002. The standardization of terminology of lower urinary tract function: report from the standardisation sub-committee of the International Continence Society. Neurourology and Urodynamics 21:167-178

5- Minassian VA, Drutz HP, Al-Badr A. 2003. Urinary incontinence as a worldwide problem. International Journal of Gynecology and Obstetetrics 82:327-338

6- Kocak I, Okyay P, Dundar M, Erol H, Beser E. 2005. Female urinary incontinence in the West of Turkey: prevalence, risk factors and Impact on Quality of Life. European Urology 48:634-641

7- Hampel C, Wienhold D, Benken N,Eggersmann C, Thuroff JW. 1997. Prevalence and natural history of female incontinence. European Urology 32(Suppl2):3-12

8- Bo K, Talseth T, Holme I. 1999. Single blind, randomized controlled trial of pelvic floor exercises, electrical stimulation, vaginal cones and no treatment in management of genuine stress incontinence in women. BMJ 318:487-493

9- Ebbesen MH, Hunskaar S, Rortveit G,Hannestad YS. 2013. Prevalence, incidence and remission of urinary incontinence in women: longitudinal data from the Norwegian HUNT study (EPINCONT). BMC Urology 13:27. Doi:10.1186/1471-2490-13-27

10- Mäkinen JI, Grönroos M, Kiilholma PJA, Tenho TT, Pirhonen JP, Erkkola RU. 1992.

The prevalence of incontinence in a randomized population of 5247 adult Finnish women. International Urogynecology Journal 3(2):110-113

11- Bo K, Haakstad LAH, Voldner N. 2007. Do pregnat women exercise their pelvic Floor muscles? International Urogynecology Journal 18:733-736 
420

421

422

423

424

425

426

427

428

429

430

431

432

433

434

435

436

437

438

439

440

441

442

443

444

445

446

447

448

449

12- Maral I, Ozkardes, H, Peskircioglu L, Bumin MA. 2001. Prevalence of stress urinary incontinence in both sexes at or after age 15 years: a cross-sectional study. Journal of Urology 165:408-412

13- Ozerdogan N, Kizilkaya Beji N, Yalcin O. 2004. Urinary incontinence: its prevalence, risk factors and effects on the quality of life of women living in a region of Turkey. Gynecologic and Obstetric Investigation 58:145-150

14- Filiz TM, Uludag C, Cinar N, Gorpelioglu S, Topsever P. 2006. Risk factors for urinary incontinence in Turkish women. A cross-sectional study.Saudi Medical Journal 27(11):1688-92

15- Cetinel B, Demirkesen O, Tarcan T, Yalcin O, Kocak T, Senocak M, Itil I.2007. Hidden female urinary incontinence in Urology and Obstetrics and Gynecology Outpatient Clinics in Turkey: what are the determinants of bothersome urinary incontinence and help-seeking behavior? International Urogynecology Journal 18:659-66416- Kocaoz S, Talas MS, Atabekoglu CS. 2010. Urinary incontinence in pregnant women and their quality of life. Journal of Clinical Nursing 19:3314-3323 doi: 10.1111/j.1365 2702.2010.03421

17- Thom D, Brown JS. 1998. Variation in estimates of urinary incontinence prevalence in the community: effects of differences in definition, population characteristics, and study type. Journal of American Geriatrics Society 46:473-480

18- Elving LB, Foldspang A, Lam GW. 1989. Descriptive epidemiology of urinary incontinence in 3,100 women age 30-59. Scandinavian Journal of Urology and Nephrology Supplement 125:37-43

19- Brown JS, Grady D, Ouslander JG, Herzog AR, Varner RE, Posner SF. 1999. Prevalence of urinary incontinence and associated risk factors in postmenopausal women. Heart and Estrogen/Progestin Replacement Study (HERS) Research Group. Obstetrics and Gynecology 94(1):66-70

20- Buchsbaum GM, Chin M, Glantz C. 2002. Prevalence of urinary incontinence and associated risk factors in a cohort of nuns. Obstetrics and Gynecology 100:226-9

21-Bump RC, McClish DM. 1994. Cigarette smoking and pure genuine stress incontinence of urine: A comparison of risk factors and determinants between smokers and nonsmokers. American Journal of Obstetrics and Gynecology 170:579-82 
450

451

452

453

454

455

456

457

458

459

460

461

462

463

464

465

466

467

468

469

470

471

472

473

474

475

476

477

478

479

22-Falconer C, Ekman G, Malmstrom A. 1994. Decreased collagen synthesis in stresincontinent women. Obstetrics and Gynecology 84:583-6

23- Mason L, Glenn S, Walton I, Appletion C. 1999. The prevalence of stress incontinence during pregnancy and following delivery. Midwifery. 1999;15(2):120-128

24- Viktrup L, Rortveit G, Lose G. 2006. Risk of urinary incontinence twelve years after the first pregnancy and delivery. Obstetrics and Gynecology 108:248-254

25- Karan A, Aksaç B, Ayyıldız H, Işıkoğlu M, Yalçın O, Eskiyurt N. 2000. Quality of life and its relation with objective assessment parameters in urinary incontinent patients. Turkish Journal of Geriatrics 3(3): 102-626- Van Brummen HJ, Bruinse HW, Van de Pol G, Heintz APM, Van der Vaart CH. 2007. The effect of vaginal and cesarean delivery on lower urinary tract symptoms: what makes the difference? International Urogynecology Journal Including Pelvic Floor Dysfunction 18:133-139

27- Sangsawang B, Sangsawang N. 2013. Stress urinary incontinence in pregnant women: a review of prevalence, pathophysiology, and treatment. International Urogynecology Journal 24:901-12

28- Hunskaar S, Burgio K, Clark A, Lapitan MC, Nelson R, Sillen U, Thom D. 2005. Epidemiology of urinary incontinence (UI) and feacal incontinence (FI) and pelvic organ prolapsed (POP). In incontinence (Abrams P, Cardozo L, Khoury S, Wein A eds). 3rd International Consultation on Incontinence. Health Publication Vol 1: Basics \& Evaluation, Chapter 5.pp.255-312

29- Sharma JB, Aggarwal S, Singhal S, Kumar S, Roy KK. 2009. Prevalence of urinary incontinence and other urological problems during pregnancy: a questionnaire based study. Archives of Gynecology and Obstetrics 279:845-51

30- Bump RC, Norton PA. 1998. Epidemiology and natural history of pelvic floor dysfunction. Obstetrics and Gynecology Clinics of North America 25:723-746

31- Samuelsson EC, Victor FTA, Svardsudd KF. 2000.Five year incidence and remission rates of female urinary incontinence in a Swedish population less than 65 years old. American Journal of Obstetrics and Gynecology 183:568-74

32- Wesnes SL, Rordvit G, Bo K, Hunskaar S. 2007. Urinary incontinence during pregnancy. Obstetrics and Gynecology 109:922-928 
480

481

482

483

484

485

486

487

488

489

490

491

492

493

494

495

496

497

498

499

500

501

502

503

504

505

506

507

508

33- Scarpa KP, Herrmann V, Palma PCR, Riccetto CLZ, Morais SS. 2006. Prevalence and correlates of stress urinary incontinence during pregnancy: a survey at UNICAMP Medical School, Sa o Paulo, Brazil. International Urogynecology Journal 17:219-223

34- Seshan V and Muliira JK. 2013. Self-reported urinary incontinence and factors associated with symptom severity in community dwelling adult women: implications for women's health promotion. BMC Women's Health 13:16

35- Zhu L, Lang J, Liu C, Han S, Huang J and Li X. 2009. The epidemiological study of women with urinary incontinence and risk factors for stress urinary incontinence in China, Menopause:The Journal of The North American Menopause Society 16 (4): 831/836, DOI:0.1097/gme.0b013e3181967b5d

36- Vahdatpour B, Zargham M, Chatraei M, Bahrami F, and Alizadeh F. 2015. Potential risk factors associated with stress urinary incontinence among Iranian women. Advanced biomedical research [electronic resource]. 4:205. Published online 2015 Sep 28. doi: $10.4103 / 2277-9175.166141$

37- Findik RB, Unluer AN, Şahin E, Bozkurt OF, Karakaya J, Unsal A. 2012. Urinary incontinence in women and its relation with pregnancy, mode of delivery, connective tissue disease and other factors, Advances in Clinical and Experimental Medicine. 21(2): 207-213. 38- Townsend MK, Danforth KN, Rosner B, Curhan GC, Resnick NM, Grodstein F. 2007. Body mass index, weight gain, and incident urinary incontinence in middle-aged women. Obstetrics and Gynecology 110:346-356

39- Hunskaar S. 2008. A systematic review of overweight and obesity as risk factors and targets for clinical intervention for urinary incontinence in women. Neurourology and Urodynamics. 27(8):749-57

40- Hansen BB,Svare J, Viktrup L, Jørgensen T, and Gunnar Lose G.2012. Urinary incontinence during pregnancy and 1 year afterdelivery in primiparous women compared with a control group of nulliparous women. Neurourology and Urodynamics 31:475-480.

41- Abdullah B, Ayub SH, Mohd Zahid AZ, Noorneza AR, Mohamad Rodi Isa, Ng PY. 2016. Urinary incontinence in primigravida: the neglected pregnancy predicament, European Journal of Obstetrics \& Gynecology and Reproductive Biology. 198:110-115 
509 42- Pahor M, Manini T, and Cesari M. 2009 October. Sarcopenia: clinical evaluation, 510 biological markers and other evaluation tools. The Journal of Nutrition, Health \& Aging. 511 13(8): 724-728

512 43- Sangsawang B and Sangsawang N. 2016. Is a 6-week supervised pelvic floor muscle 513 exercise program effective in preventing stress urinary incontinence in late pregnancy in 514 primigravid women?: a randomized controlled trial, European Journal of Obstetrics \& 515 Gynecology and Reproductive Biology.197:103-110

516 44-Walker GJA and Gunasekera P. 2011 Feb. Pelvic organ prolapse and incontinence in 517 developing countries: review of prevalence and risk factors, International 518 Urogynecology. 22(2):127-35. doi: 10.1007/s00192-010-1215-0. Epub 2010 Jul 9

519 45- Scherf C, Morison L, Fiander A, Ekpo G, Walraven G. 2002. Epidemiology of pelvic 520 organ prolapse in rural Gambia, West Africa. British Journal of Obstetrics and Gynaecology $521 \quad 109: 431-436$

522 46- Bodner-Adler B, Shrivastava C, Bodner K. 2007. Risk factors for uterine prolapse in 523 Nepal. International Urogynecology Journal Including Pelvic Floor Dysfunction 18:1343$524 \quad 1346$

525 47-Adamczuk J, Szymona-Pałkowska K, Robak JM, Rykowska-Górnik K,Steuden S, 526 Kraczkowski JJ. 2015. Coping with stress and quality of life in women with stress urinary 527 incontinence. Przeglad menopauzalny = Menopause review. 14(3): 178-183. DOI: $528 \quad 10.5114 / \mathrm{pm} .2015 .54342$ 


\section{Table 1 (on next page)}

Socio-demographic features of the participants 
1 Table 1 Socio-demographic features of the participants

2 Urinary Incontinence

\begin{tabular}{|c|c|c|c|c|}
\hline & Present & Absent & Total & Statistics \\
\hline Socio-demographic features & $\mathrm{n}=56(\%)$ & $\mathrm{n}=76(\%)$ & $\mathrm{n}=132(\%)$ & $\mathrm{P}$ \\
\hline Age (years), mean \pm Sd & $26.7 \pm 5.4$ & $28.2 \pm 4.9$ & $27.5 \pm 5.1$ & $0.780^{\$}$ \\
\hline Age group (years) & & & & $0.146^{\$}$ \\
\hline $18-35$ & $50(89.3)$ & $69(90.8)$ & $119(90.2)$ & \\
\hline$\geq 35$ & $6(10.7)$ & $7(9.2)$ & $13(9.8)$ & \\
\hline Height (cm) & & & & $0,037{ }^{\$ *}$ \\
\hline $\begin{array}{l}\text { Median } \\
\text { (Min-Max) }\end{array}$ & $\begin{array}{l}160,0 \\
(153.0-176.0)\end{array}$ & $\begin{array}{l}160,0 \\
(147.0-173.0)\end{array}$ & $\begin{array}{l}160,0 \\
(147.0-176.0)\end{array}$ & \\
\hline BMI (kg/m²) & & & & $0.881^{\$}$ \\
\hline $\begin{array}{l}\text { Median } \\
\text { (Min-Max) }\end{array}$ & $\begin{array}{l}28.7 \\
(22.4-50.0)\end{array}$ & $\begin{array}{l}29.2 \\
(22.5-50.7)\end{array}$ & $\begin{array}{l}29.1 \\
(22.4-50.7)\end{array}$ & \\
\hline Education & & & & $0.016^{£^{*}}$ \\
\hline Primary school & $11(19,6)$ & $32(42,1)$ & $43(32,6)$ & \\
\hline Intermediate & $11(19.6)$ & $5(6.6)$ & $16(12.1)$ & \\
\hline High school & $19(33.9)$ & $24(31.6)$ & $43(32.6)$ & \\
\hline University & $15(26.8)$ & $15(19.7)$ & $30(22.7)$ & \\
\hline Occupation & & & & $0.122^{£}$ \\
\hline Working & $21(37,5)$ & $19(25)$ & $40(30.3)$ & \\
\hline Not-working & $35(62,5)$ & $57(75)$ & $92(69.7)$ & \\
\hline
\end{tabular}




\section{Table 2 (on next page)}

Presence of urinary incontinence $(\mathrm{UI})$ with respect to multiple pregnancy, interval between pregnancies, miscarriage, gestational weeks, parity and anemia 
Table 2 The statistical analysis of presence of urinary incontinence (UI) with respect to multiple pregnancy, interval between pregnancies, miscarriage, gestational weeks, parity and anemia

\begin{tabular}{|c|c|c|c|c|}
\hline & $\underline{\text { UI Present }}$ & $\underline{\text { UI Absent }}$ & Overall & $\underline{\text { Statistics }}$ \\
\hline Variables & $\mathrm{n}(\%)$ & $\mathrm{n}(\%)$ & $\mathrm{n}(\%)$ & $\mathrm{P}$ \\
\hline Multiple pregnancy (n, \%) & & & & $0.747^{£}$ \\
\hline $\begin{array}{l}\text { Present } \\
\text { Absent }\end{array}$ & $\begin{array}{l}1(1.8 \%) \\
55(98.2 \%)\end{array}$ & $\begin{array}{l}2(2.6 \%) \\
74(97.4 \%)\end{array}$ & $\begin{array}{l}3(2.3 \%) \\
129(97.7 \%)\end{array}$ & \\
\hline $\begin{array}{l}\text { Interval between pregnancies }(\mathrm{n}, \%) \\
\text { primigravida } \\
<2 \text { years } \\
2-5 \text { years }\end{array}$ & $\begin{array}{l}29(51.8) \\
17(30.4) \\
6(10.7)\end{array}$ & $\begin{array}{l}33(43.4) \\
18(23,7) \\
14(18.4)\end{array}$ & $\begin{array}{l}62(47.0) \\
35(26.5) \\
20(15.2)\end{array}$ & $0.283^{\mathfrak{f}}$ \\
\hline$>5$ years & $4(7.1)$ & $11(14.5)$ & $15(11.4)$ & \\
\hline $\begin{array}{l}\text { Miscarriage (n, \%) } \\
\text { Present } \\
\text { Absent }\end{array}$ & $\begin{array}{l}16(28.6) \\
40(30.3)\end{array}$ & $\begin{array}{l}18(23.7) \\
58(76.3)\end{array}$ & $\begin{array}{l}34(25.8) \\
98(74,2)\end{array}$ & $0,526^{£}$ \\
\hline $\begin{array}{l}\text { Gestational weeks } \\
\text { Median } \\
\text { (Min-Max) }\end{array}$ & $\begin{array}{l}38 \\
(33.0-40.0)\end{array}$ & $\begin{array}{l}38 \\
(33.0-40.0)\end{array}$ & $\begin{array}{l}38 \\
(33.0-40.0)\end{array}$ & $0.908^{\$}$ \\
\hline $\begin{array}{l}\text { Parity } \\
\text { Median } \\
\qquad \text { (Min-Max) }\end{array}$ & $\begin{array}{l}1.0 \\
1-4\end{array}$ & $\begin{array}{l}2.0 \\
1-8\end{array}$ & $\begin{array}{l}2.0 \\
1-8\end{array}$ & $0.358^{\$}$ \\
\hline $\begin{array}{c}\text { Anemia }(\mathbf{n} \%) \\
\text { Present } \\
\text { Absent }\end{array}$ & $\begin{array}{l}22(39,3) \\
34(60.7)\end{array}$ & $\begin{array}{l}31(40.8) \\
45(59.2)\end{array}$ & $\begin{array}{l}53(40.2) \\
79(59.8)\end{array}$ & $0.862^{£}$ \\
\hline
\end{tabular}

${ }^{£}$ Chi-square $\left(\chi^{2}\right)$ test, ${ }^{\$}$ Mann-Whitney test 


\section{Table 3(on next page)}

Frequency and amount of leakage in pregnant women with urinary incontinence 
1

2

3

4

Table 3 Frequency and amount of leakage in

6

pregnant women with urinary incontinence (UI) $(\mathbf{n}=56)^{£}$

\section{Characteristics of UI}

(\%)

\section{Frequency}

Never

$3(5.4)$

Once a week or less

$18(32.1)$

Twice or three times a week

$8(14.3)$

Once a day

$5(8.9)$

Few times a day

$14(25.0)$

Always

$8(14.3)$

$\begin{array}{ll}\text { Amount } & \\ \text { None } & 15(26.8) \\ \text { Small } & 33(58.9) \\ \text { Moderate } & 4(7.1) \\ \text { Large } & 4(7.1)\end{array}$

7

${ }^{£}$ Chi-square $\left(\chi^{2}\right)$ test

8

9 
Table 4 (on next page)

Impact on quality of life (QOL) of pregnant women with urinary incontinence 
1

2

3

4

5

Table 4 Impact on quality of life (QOL) of pregnant women with urinary incontinence (UI) ${ }^{\sharp}$

6

QOL Score

\begin{tabular}{llll} 
Impact on QOL & $\mathbf{n = 5 6}(\mathbf{\%})$ & Mean & sd \\
\hline & $15(26.8)$ & 0 & 0 \\
(0)Not at all & $33(58.9)$ & 10.1 & 7.2 \\
(1-28) Mild & $4(7.1)$ & 36.3 & 5.4 \\
(29-56) Moderate & $4(7.1)$ & 66.4 & 6.3 \\
(57-84) Severe &
\end{tabular}

7

${ }^{\ddagger}$ Kruskal-Wallis Test

8

9 


\section{Table 5 (on next page)}

Table 5 Life style changes due to urinary incontinence among pregnant women 
Table 5 Life style changes in urinary incontinence group $(n=56)$

Item impacted

Affect shopping or excursions outside the home

Affect working performance and friendship

Affect daily home activities

Affect general health status

Affect sexual relations

Makes you nervous and anxious

Need wearing pad or protector n $\quad(\%)$

$13 \quad(23.2 \%)$

$5 \quad(8.9 \%)$

$4 \quad(7.1 \%)$

$7 \quad(12.5 \%)$

$7 \quad(12.5 \%)$

$6 \quad(10.7 \%)$

$14 \quad(25.0 \%)$ 
Table 6(on next page)

Table 6 Logistic Analyses of predisposing Factors for Urinary Incontinence 
3

\begin{tabular}{|c|c|c|c|c|c|c|c|}
\hline Variables for developing UI & B & SE & df & $\mathbf{P}$ & OR & $95 \% \mathrm{CI}$ & $95 \% \mathrm{CI}$ \\
\hline & & & & & & Lower & Upper \\
\hline Age & -0.154 & 0.556 & 1 & 0.782 & 0.845 & 0.268 & 2.669 \\
\hline Miscarriage & 0.996 & 0.296 & 1 & $0.002 *$ & 1.219 & 0.588 & 2.825 \\
\hline Occupational status & 0.511 & 0.276 & 1 & 0.064 & 1.800 & 0.850 & 3.81 \\
\hline BMI & 0.013 & 0.041 & 1 & 0.998 & 1.000 & 1.000 & 1.000 \\
\hline Anemia & 0.435 & 0.274 & 1 & 0.112 & 0.939 & 0.464 & 1.901 \\
\hline Parity & 0.656 & 0.239 & 1 & $0.006 *$ & 0.519 & 0.325 & 0.829 \\
\hline Rural vs urban & -0.642 & 0.276 & 1 & $0.020 *$ & 1.800 & 0.887 & 3.653 \\
\hline
\end{tabular}


Table 7 (on next page)

Table 7 Evaluation of standard deviations 
1

2

3

Table 7 Evaluation of Standart deviations of QOL analyses

5 QOL

\begin{tabular}{|c|c|c|c|c|c|}
\hline & $\begin{array}{l}\text { Sum of } \\
\text { Squares }\end{array}$ & $\mathrm{df}$ & Mean Square & $\mathrm{F}$ & $\mathrm{P} *$ \\
\hline Between & 19882.17 & \multirow{2}{*}{2} & \multirow{2}{*}{9941.088} & \multirow{5}{*}{179.126} & \multirow{5}{*}{$0.000 *$} \\
\hline Groups & 6 & & & & \\
\hline Within Groups & 2941.378 & 53 & 55.498 & & \\
\hline \multirow[t]{2}{*}{ Total } & 22823.55 & \multirow{2}{*}{55} & & & \\
\hline & 4 & & & & \\
\hline
\end{tabular}

6

7

8

* ANOVA test, Significant

9

10

11

12 


\section{Table 8(on next page)}

Tbale 8 Clinical relevance of results 
Table 8 Clinical relevance of statistically significant results by multiple comparisons test

\section{Multiple Comparisons}

Dependent Variable: QOL

\begin{tabular}{|c|c|c|c|c|c|c|c|}
\hline & (I) Grup & (J) Grup & $\begin{array}{l}\text { Mean Difference } \\
\text { (I-J) }\end{array}$ & $\begin{array}{l}\text { Std. } \\
\text { Error }\end{array}$ & $\mathrm{P}^{*}$ & \multicolumn{2}{|c|}{ 95\% Confidence Interval } \\
\hline & & & & & & Lower & \\
\hline & & & & & & Bound & Upper Bound \\
\hline \multirow{7}{*}{$\begin{array}{l}\text { Tukey } \\
\text { HSD }\end{array}$} & & Moderate & 31080 & 3512 & $0000 *$ & 30557 & 20621 \\
\hline & Mild & Moderate & -31.089 & 3,312 & $0,000^{*}$ & -39.531 & -22.621 \\
\hline & & severe & -56.956 & 3,238 & $0,000^{*}$ & -64.763 & -49.149 \\
\hline & Moderate & Mild & 31.089 & 3,512 & $0,000^{*}$ & 22.621 & 39.557 \\
\hline & & severe & -25.867 & 4,511 & $0,000^{*}$ & -36.744 & -14.989 \\
\hline & severe & Mild & 56.956 & 3,238 & $0,000 *$ & 49.149 & 64.763 \\
\hline & & Moderate & 25.867 & 4,511 & $0,000 *$ & 14.989 & 36.744 \\
\hline \multirow[t]{6}{*}{ Tamhane } & Mild & Moderate & -31.089 & 4,554 & $0,005 *$ & -47.917 & -14.261 \\
\hline & & severe & -56.956 & 2,666 & $0,000 *$ & -65.195 & -48.716 \\
\hline & Moderate & Mild & 31.089 & 4,554 & $0,005 *$ & 14.261 & 47.917 \\
\hline & & severe & -25.867 & 5,045 & $0,005 *$ & -42.090 & -9.644 \\
\hline & severe & Mild & 56.956 & 2,666 & $0,000^{*}$ & 48.716 & 65.195 \\
\hline & & Moderate & 25.867 & 5,045 & $0,005^{*}$ & 9.644 & 42.090 \\
\hline
\end{tabular}

*Significant 